\title{
Determinants of Food Security in the Home on Nutritional Status of Adolescent Students in Abia, State
}

\author{
${ }^{1}$ Alozie, Elsie Nkemdilim and ${ }^{2}$ Bassey E. Anam \\ ${ }^{I}$ Department of Home Economics/Hospitality Management and Tourism \\ Michael Okpara University of Agriculture, Umudike State, Nigeria \\ ${ }^{2}$ Institute of Public Policy \& Administration, University of Calabar, Nigeria
}

\begin{abstract}
The study was designed to investigate the determinants of food security in the home and its effect on nutritional status of adolescent's students in Abia State of Nigeria. Five specific purpose and five null hypotheses were formulated to guide the study. A survey design was used for the study. 2000 students constituted the population while 500 respondents were the sample for the study. The researcher developed instrument named Food Security variables and Students Nutritional Status Questionnaire (FSVS NSQ) was used for data generation. Pearson Product Moment Correlation (PPMC) and Multiple Regression Analysis were used to analyse the five null hypotheses 1, 4 and 5 respectively at 0.05 alpha level and 498 degree of freedom. The findings revealed that there is joint relationship between food availability acceptability, affordability, sustainability and nutritional status of students in Abia State. Some recommendations were made such as School administration should encourage hand-on experiences in agriculture at all levels, as a means of creating awareness among children of the benefits of food production for improved nutritional status and its resultant effects.
\end{abstract}

Keywords: Food Security, Food Accessibility, Food Availability, Food Affordability, Food Suitability Nutritional Status.

\section{Background of the study}

Food security has been the main concern of Government in many countries of the world. The resent world food crisis that led to starvation in many nations also has its devastating effects particularly on developing rations nutritionally. Poor nutrition (a condition of under-nourishment) continues to be a worldwide problem. According to the report Food and Agriculture Organization (FAO) of the United Nations (2006), there is food inadequacy in many nations of the world. The report also indicated that 880 million people worldwide were undernourished between 1999 and 2005. In most recent years, for which figures are available, the number of poorly-nourished people has increased.

Although various policy measures have been designed to address the problem, and despite the implication of major market liberalization in the country as well as surpluses of food giving production in recent years. There has been report that food availability still remains at low level and food security persists. Food security emerged as a key problem and development challenge in Nigeria. a host of factors including natural and manmade has resulted to the on-going food insecurity problems in different parts of the country frequently reoccurring droughts and erratic rainfall patterns, land degradation rapid population growth and poor rural infrastructure has also been cited as one of the causes of food insecurity and misread poverty in the country. Other factors contributing to food insecurity are the low levels of technology employed in agriculture and resulting to low production of the sector (Sabates-wheeler et al 2012).

The concept of food insecurity encompasses multiple dimensions such as food production access and absorption. Factors that may lead to the situation of food insecurity, therefore include non-availability accessibility affordability and sustainability hence the determinant of household food security in effect composes the factors that determines each component of food security. In general, the determinants of food security are different at different levels of application i.e. global national regional, household and individual levels (Khan et al 2010). An orange awareness ribbon is used to raise awareness of poor nutrition in the world. Usually it is a measure of condition majorly in children under 10 years of age. This definition refers to the amount of food available in that country (FAO 2006). The most common justification for food insecurity is economic poverty in the society. Economic poverty has been known to contribute immensely to poor nutritional status among the youths (Dalakar 2006). Nutritional status therefore, of children in Abia State of Nigeria seems to be influenced by variables of food availability, accessibility, affordability and suitability. This is because the bulk of food production is at peasantry level through subsistence agricultural practices by farmers in the rural locations of the state. 
Food availability has to do with having food in adequate quantity for consumption by individuals and families (Cormik 1998). Food accessibility involves individuals and families having access to available food at all times while food affordability entails individuals and families possessing purchasing power to acquire the needed food stuff (Jennifer 2005). Food suitability has to do with having quality food with necessary information value to sustain body metabolism. Food security involves having available food in adequate quantity and quality with all necessary nutritional values to sustain body metabolism of individuals and families. Nutritional status therefore consists of having food available, accessible, suitable and affordable to individuals and families (Usanga 2003).

\section{Statement of the problem}

At present, most Nigerians, especially those in the rural areas live below poverty line, due to insufficient money to feed oneself family. These individuals consume more carbohydrates and less proteins, vitamins and minerals and therefore prone to considerable malnourishment. (Eleanor Among the most vulnerable persons is the children (Williams 2005). Williams had also observed that parents in some families cannot afford three balanced meals for their children in a day. Moreover, the little they could afford is deficient in essential nutrients combinations of carbohydrates, protein, vitamins and minerals. Rural economic poverty is a dominant feature in Nigeria as observed among rural population whose income and consumption levels are below the national defined poverty lines (Morduch 1990).

In Nigeria the rural poor are estimated to be $60 \%$ (Usanga 2003). Although poverty is a global problem, it is most devastating in developing nations like Nigeria. This is attributed to the somewhat sharp decrease in real income, low food production level, massive deterioration in health care that affect children most. The observed imbalance in nutritional status of children could be predicated on food scarcity due to low food production and therefore poor food consumption. The resultant effect of course, is starvation and hunger. It is imperative to examine the relationship between food availability, accessibility, affordability suitability and the nutritional status of children in Abia State of Nigeria, especially in these days of world economic meltdown and food insecurity.

\section{Purpose of the study}

This study examines influence of food security determinants on nutritional status of secondary school students in Abia State. Specifically the study determined the relationship between;

1. Food availability and nutritional status of students in Abia State.

2. Food accessibility and nutritional status of students in Abia State.

3. Food affordability and nutritional status of students in Abia State.

4. Food suitability and nutritional status of students in Abia State and also;

5. Determined the joint relationship between food availability, accessibility, affordability, suitability and the nutritional status of student in Abia State.

\section{Hypotheses}

The following hypotheses were formulated and stated at 0.05 alpha level.

1. There is no relationship between food availability and nutritional status of students in Abia State.

2. There is no relationship between food accessibility and nutritional status of students in Abia State.

3. There is no relationship between food affordability and nutritional status of students in Abia State.

4. There is no relationship between food suitability and nutritional status of students in Abia State.

5. There is no joint relationship between food availability, accessibility, affordability, suitability and nutritional status of students in Abia State.

\section{Literature Review}

Food and Nutrition Policies can be used to address some of the problems of food security. In most countries including the United Kingdom today, nutrition suffers from the lack of clear government policies (Edafe and Ohwovoriole, 2002). This they said is attributed to the fact that decision affecting food and nutrition are made in several different ministries, such as ministries of Agriculture, Health, Education and Trade. Passmore and Eastwood (1986) noted that some of these ministries have nutritional advisers. Ministerial decisions are based on many sectional interests and infrequently conflicting with nutritional policies. For Nigeria, beginning with a national conference in 1979, the development of a national food and nutrition policy evolved over a number of years. Following another conference in 1989, the National Committee on Food and Nutrition was established as an inter-ministerial body, hosted first by the National Agency for Science and Engineering (NASEN) and then after 1993, by the Federal Ministry of Health. 
Despite improvement in global food availability over time, many developing countries remain vulnerable to food insecurity. World Bank (1996) defined food security as the access by all people at all times to enough food for an active and healthy life. Food and Agricultural Organization (1996) is of the view that food security exist when all people at all times have physical and economic access to sufficient, safe and nutritious food to meet their dietary need and food preferences for an active and healthy life. Nutrition security is what every family in Nigeria needs because in addition to ensuring access to adequate quantity of food, assures adequate quality, safety of foods and water, proper intra-household food distribution, taking into account the Lords (1995), availability of food is a function of increased food production, stake holding an $\mathrm{d}$ trade. Access to food by households and individuals is conditioned by income distribution and poverty, since the poor lack adequate means to secure access to food.

\section{Design of the study}

\section{Methodology}

A survey design was used for the study. The design assist the researchers to generate data from a sample of the JSS students; population from the schools within the rural communities in the 17 Local Government Area of Abia State.

\section{Area of the study}

The area is the rural communities in the 17 Local Government Areas of Abia State. The rural communities are those communities located 10 kilometres away from local government's administrative headquarters. The inhabitants are primarily engaged in farming which is mostly subsistence, for the family. They experience the problem of imbalanced meals and irregular timing of eating the meals. Economically, they are not strong to afford the essentials of life when needed.

\section{Population of the study}

The population for the study comprised all the two hundred and twenty eight secondary schools in Abia State. Junior Secondary School Two (JSS 2) students were involved in the study with a population of 2000 students.

\section{Sample and sampling technique}

Samples of five hundred students were selected through simple random sampling technique. 10 schools were randomly selected. From each school fifty Students were drawn giving a sample size of 500 respondents.

\section{Instrumentation}

The researcher developed, five sectioned instrument named-Food Security Variables and students Nutritional Status Questionnaire (FSVSNSQ) was used in generating data for the study. Section A of the instrument deals with students Biodata. Section B, C, D, and E sought information on the variables (food availability, accessibility, affordability, suitability) and nutritional status of student in Abia State.

\section{Instrument Validation}

The instrument was validated by five experts in the Department of Vocational Education, Faculty of Education, Abia State University Uturu and MOUAU. Inputs from these experts were incorporated into the final draft of the instrument.

\section{Reliability of the Instrument}

A test-retest procedure was used for testing the reliability of the instrument. A group of 50 respondents not included in the study were administered and re-administered with the instrument at two weeks intervals. The reliability coefficient was established using Pearson Product Moment Correlation (PPMC) which yielded reliability coefficient of $\mathrm{r}=0.92 \mathrm{P}<0.05$. The coefficient value was considered high enough to make the instrument suitable for the study.

\section{Data Analysis Technique}

Data generated from the study were analyzed using Pearson Product Moment Correlation (PPMC) in testing null hypotheses 1-4 while Multiple Regression Analysis was used in testing hypothesis 5.

\section{Result and Discussion of Findings}

The results of the findings were discussed based on statistical evidence.

\section{Null Hypotheses 1}

1. There is no relationship between food availability and nutritional status of students in Abia State. 
Table 1

Relationship between Food Availability and Nutritional Status of Students

$\begin{array}{lcccccr}\text { Variable } & \sum \mathrm{x} \sum \mathrm{y} & \sum \mathrm{x}^{2} \sum \mathrm{y}^{2} & \sum \mathrm{xy} & \text { Df } & \text { r-cal. } & \text { r-crit. } \\ \text { Food Availability } & 3240 & 10497606 & & & & \\ & & & 8216640 & 498 & 0.72 & 0.063\end{array}$

Students' Nutritional

Status $2536 \quad 2431296$

Source: Field survey 2008; $\mathrm{N}=500 ; *$ = Significant at $\mathrm{P}<0.05$ alpha level.

Data presented in table 1 revealed that the calculated r-value of 0.72 was greater than the critical $r$-value of 1.063 at df of 498 and 0.05 alpha level. Therefore, the null hypothesis stating that there is no significant relationship between food availability and nutritional status of children was rejected. This implies that there is significant relationship between food availability and nutritional status of children in Abia State.

\section{Null Hypothesis 2}

There is no relationship between food accessibility and nutritional status of students in Abia State.

Table 2

There is no relationship Between Food Affordability and Nutritional Status of students.

$\begin{array}{lllllll}\text { Variable } & \sum \mathrm{x} \sum \mathrm{y} & \sum \mathrm{x}^{2} \sum \mathrm{y}^{2} & \sum \mathrm{xy} & \text { Df } & \text { r-cal. } & \text { r-crit. } \\ \text { Food Affordability } & 3455 & 11937025 & & & & \\ & & & 8761880 & 498 & 0.59 & 0.063\end{array}$

Students' Nutritional

Status $2536 \quad 2431296$

Table 2 showed that the calculated r-value of 0.59 was greater than the critical $r$-value of 0.003 at of 498 and 0.05 alpha level. Therefore, the null hypothesis stating that is no relationship between food accessibility nutritional status of students in Abia State was rejected. This implies that there is relationship between food accessibility and nutritional status of students in Abia State.

\section{Null Hypothesis 3}

There is no relationship between food affordability and the nutritional status of students in Abia State.

Table 3

Relationship between Food Affordability and Nutritional Status of Children

$\begin{array}{lcccccc}\text { Variable } & \sum \mathrm{x} \sum \mathrm{y} & \sum \mathrm{x}^{2} \sum \mathrm{y}^{2} & \sum \mathrm{xy} & \mathrm{Df} & \text { r-cal. } & \text { r-crit. } \\ \text { Food Availability } & 3357 & 11590625 & & & & \end{array}$

Students' Nutritional

Status $2536 \quad 6431296$

Source: Field survey 2008; N=500; * Significant at $\mathrm{P}<0.05$ alpha level.

Data presented in table 3 revealed that the calculated r-value of 0.83 was greater than critical r-value of 0.063 at df of 498 and 0.05 alpha level. Therefore, the null hypothesis stating that there is no relationship between food affordability and nutritional status of students was rejected. This implies that there is between food affordability and nutritional status of children in Abia State.

\section{Null Hypothesis 4}

There is no relationship between food suitability and the nutritional status of student in Abia State.

Table 4

Relationship between food suitability and nutritional Status of Students

$\begin{array}{lcccccc}\text { Variable } & \sum \mathrm{x} \sum \mathrm{y} & \sum \mathrm{x}^{2} \sum \mathrm{y}^{2} & \sum \mathrm{xy} & \text { Df } & \text { r-cal. } & \text { r-crit. } \\ \text { Food Availability } & 3195 & 10208025 & & & & \end{array}$

Students' Nutritional

Status

$2536 \quad 8102520$

Source: Field survey 2008; N =500; * = Significant at $\mathrm{P}<0.05$ alpha level. 
Table 4 indicated that the calculated r-value of 0.68 was greater than the critical r-value of 0.063 at 498 df and 0.05 alpha level. Therefore the null hypothesis stating that the there is no relationship between food suitability and nutritional status of students was rejected. This implies that there is relationship between food suitability and nutritional status of students in $\langle>$ Abia State $<>$ Null Hypothesis 5 There is no joint relationship between food availability, accessibility, affordability, suitability and nutritional status of students in Abia State.

Table 5

Relationship between Food Security Variables and Nutritional Status of Students

$\begin{array}{lllll}\text { Source Variation } & \text { Df } & \begin{array}{l}\text { Sum of } \\ \text { square }\end{array} & \begin{array}{l}\text { Mean of } \\ \text { Square }\end{array} & \text { F-ratio }\end{array} \quad$ F-value

$\begin{array}{llllll}\text { Food Availability } & 1 & 2184.13 & 2184.13 & & \\ \text { Within Group } & 497 & 28343.61 & 59.11 & & \\ \text { Total } & 498 & 30527.61 & & & \\ \text { Regression Coefficient } & \mathrm{R} & =0.6382 & & \\ \text { Regression Coefficient } & \mathrm{R}^{\prime} & =0.7073 & & \\ \text { Standard Error } & & =4.3350 & & \end{array}$

Source: Field survey 2008; N=500; df 498; * = at P < 0:05 alpha level.

Data presented in table 5 revealed that the regression coefficient value of $R=0.6382$-indicating that there was relationship between food security variables. Food availability, accessibility, affordability and suitability as well as the nutritional status of students. Food scarcity results in the students being fed with food stuff containing low nutrients. Insufficient intake of balance diet also leads to retarded growth and development in students. Crash diets, which unfortunately are common among the students, result in form of malnutrition. Generally, students do not eat enough balanced foods that would provide the essential nutrients to satisfy needs.

\section{Food Accessibility and Nutritional Status of Students}

The study also indicated a relationship between food accessibility and nutritional status of students in Abia State. (See table 2). The problem of food inaccessibility could be associated with lack of money to pay for large quantity of food, lack of money to meet food budget leading of homes leading to borrowing and the spending of the family income on food and in some instances buying on credit. This finding is support Chandy (2001) who noted that consumption and savings depended on the individual family income, and the income levels in the city or town in which they family lived. Many families in Abia State do not have easy access to qualify food due to low income and general economic poverty. The result of course is the poor nutritional status of school children.

\section{Food Affordability and Nutritional Status of Children}

The result revealed that there is relationship between food affordability and nutritional status of students in Abia State (See table 3). The affordability relationship with nutritional status of students include; lack of adequate food supply and enhanced feeding programmes, lack of planning for balance diet, poor choice of food, lack of food supplements including essential vitamins and minerals. Though food may be available in the markets but the affordability becomes a problem due to high cost of the food items.

The current world food crisis is a clear indicator that food items are not affordable by low-income families and by extension, children who are easily affected by food crisis situation (Williams 2005). The study also indicated that, the calculated F-ratio of 22.96 was greater than the critical F-value of 3.84 at df of 1 and 498 and 0.05 alpha level. Therefore, the null hypothesis stating that there is no joint relationship between food availability, accessibility, affordability, suitability and nutritional status of students in Abia State was rejected. This implies that there is relationship between food availability, accessibility, affordability, suitability and the nutritional status of students Abia State.

\section{Findings of the study}

The five hypothesis tested highlighted the following findings.

There is relationship between food availability and nutritional status of students in Abia State.

2. There is relationship between food accessibility and the nutritional status of students in Abia State

5. There is relationship between food affordability and nutritional status of students in Abia State.

4. There is relationship between food suitability and nutritional status of students in Abia State.

5. There is joint relationship between food availability, accessibility, affordability, suitability and the nutritional status of students in Abia State 


\section{Discussion of the findings}

The findings of the study were discussed under the following subheadings:

\section{Food Availability and Nutritional Status of Students}

The findings of this study revealed that there is relationship between food availability and nutritional status of students in Abia State. This findings agree with the earlier studies by Williams (2005). Which out that the situation of food scarcity, in Abia State

\section{Food suitability and Nutritional Status of Students}

The findings of the study showed that there is relationship between food suitability and nutritional status of students in Abia State (See table 4). Food suitability relate with nutritional status of children in terms of food supply, types of food, family food choice, utilization of traditional food and compromising of the family prestige. This finding is in agreement with Jennifer's observation in (2005) that food value has significant influence on children's nutritional status. Suitable food therefore informed the process of eating of quality and adequate quantity of food.

Food suitability plays an important role of supplying essential growth supports in children's nutrition. Food suitability relates with quality and sufficient quantity of food intake, balanced diet and nutrient deficiencies diseases, skipping meals and the using of water as food supplement. The findings agree with the studies in Cormik (1998) which indicated that serious nutrient shortage in human diet for an extended period due to food inadequacy, would lead to low nutritional status. The ultimate will be malnutrition due to low nutritional intake, (Web. World Bank Org.). It could therefore be held that students in. Abia State are not fed with suitable food items may not have enhanced nutritional status.

\section{Educational Implications of the study}

The study has implications for student's growth had development in Abia State. If there are fed with balanced diet, then they are bound to have raised nutritional status which will manifest in good health, good brain development for proper learning and high achievements The recommendations made in this study will promote children health care through nutritional procedure. It will also assist instructors in agricultural based food and nutrition to present instructional delivery that is relevant to the health and well-being of children and youths. The study will also have implications for curriculum planners and designers as they would incorporate information provided in this study to restructure the current Agricultural Science, and Nutrition Curricula to include essential elements for good health and raised standard of living. It is hoped that, information provided will enhance a healthy society.

\section{Recommendations}

Based on the findings of the study, the following recommendations are made;

1. Agriculture educators should always adopt teaching strategies which are practical oriented towards food production, aimed at ensuring food security and raising nutritional status of children.

2. School administration should encourage hand-on experiences in agriculture at all levels, as a means of creating awareness among children of the benefits of food production for improved nutritional status and its resultant effects.

3. Government of Abia State should consider poverty alleviation through salary increase for workers and also put in place functional micro-finance nutrition. The State ministry of health should declare war on nutrient deficiencies in families through the provision of relevant food supplements.

4. Enlightenment campaign should be conducted with community mobilization by the Ministry of Environment and Social Orientation of government on the need to provide balanced diet to children of all ages.

\section{References}

[1]. Chaudy, J. E. (2000). Malnutrition and Survival of 'Children. New York: Michael Wines.

[2]. Cormik, S. (1998). Hunger and Crime. London proceedings of national Academy of Science 5 (2)183.

[3]. Dalakar, M. S. (2006). Starvation and Deprivation: Thorgorgen Effect. New York: Diamond Publishers Co.

[4]. Food and Agricultural Organization (FAO) (2006). World Food Status and health of the underprovided. Geneva. World Food Organization Publication.

[5]. Jennifer, M. L. (2005). Nutritional supplement and children health in a case study of pre-school children in Cape Town. Journal of South African Food and Agriculture Research. Cape Town Nelson Publishers 4 (2) 58

[6]. Usanga, M. E. (2003). Fundamentals of food technology in Nigeria. Owerri: Nelson Publishers.

[7]. Web World Bank. Org. Nutritional Management. Retrieved (2007). World Bank Food Security report.

[8]. Williams, P. S. (2205). Effects of Vocational agriculture teaching models on students' performances in poultry production. Awka. International Journal of Educational Research and Development 1(1)107 -117 